\title{
Predictors of Success of Shock Wave Lithotripsy for Ureteral Stones Based on Computed Tomography Scan parameters
}

Abdelrahman A Hassan, Hussein H Mahmoud, Hassan A Mohammed and Mohammed S Abdelbaky. Urology Department, Al-Azhar Faculty of Medicine, Cairo, Egypt

\begin{abstract}
Background: For shock wave lithotripsy has proven to be an effective, safe and truly minimally invasive option for the treatment of nephrolithiasis. Various technical factors as well as patient selection can impact the success of the procedure.

Objective: The aim of this study was to identify the parameters on NCCT that may predict the success of shock wave lithotripsy (SWL) in ureteral stones.

Patients and Methods: 102 patients who underwent SWL for ureteral stones at sayed Galal University Hospital from January 2015 to August 2018 diagnosed by non-contrasted computed tomography were studied. The failure was defined as remnant stones $>4 \mathrm{~mm}$. We assessed age, sex, body mass index, stone size, location, skin-to-stone distance (SSD), presence of JJ and the presence of secondary signs (hydronephrosis, renal enlargement, perinephric fat stranding, and tissue rim sign).

Results: 102 patients with success rate $61.8 \%$, stone size, stone density were significantly associated with outcome of SWL. While SSD, JJ and secondary signs (hydronephrosis, perinephric fat stranding and tissue rim sign) were insignificant. On multivariate analysis, stone size and stone density were the independent factors affecting the outcome of SWL.

Conclusions: The study demonstrated that stone size and density are significant and independent predictors of outcome in patients with upper ureteral stones. However SSD and signs of impaction still have to be evaluated.
\end{abstract}

Keywords: Outcome, Shock Wave Lithotripsy, Ureteral Stones.

\section{INTRODUCTION}

From the beginning of its clinical introduction in the early 1980s ${ }^{(\mathbf{1})}$. Shock wave lithotripsy (SWL) has become a standard treatment for renal and ureteral calculi as a safe, effective and noninvasive modality ${ }^{(2)}$.

Radiographic assessment of the stone is important to choose the best treatment. Non-contrast computed tomography (NCCT) is recommended as the standard diagnostic imaging modality in urinary stone disease ${ }^{(3)}$. Several factors have been studied to predict the success of SWL ${ }^{(4)}$. These factors may be related to the patient (skin to stone distance: SSD), or to the stones [size, location, density (Hounsfield unit and density), and presence of JJ]. Secondary signs including the presence or absence of hydronephrosis, renal enlargement, perinephric fat stranding, and tissue rim sign are also assessed on CT $\operatorname{scan}^{(5)}$.

Identification of these factors in clinical setting will increase the efficacy and decrease the cost by reducing the number of unnecessary treatment sessions (5).

\section{AIM OF THE WORK \\ The aim of this study was to identify the parameters on NCCT that may predict the success of SWL in ureteral stones.}

\section{PATIENTS AND METHODS}

This study included 102 patients who underwent SWL at Sayed Galal Hospital from January 2015 to August 2018.

The inclusion criteria: Solitary and radio-opaque ureteric stone of size $5 \mathrm{~mm}$ to $20 \mathrm{~mm}$.
Exclusion criteria: Patients with incomplete data, missed follow up, active UTI, bleeding tendency and elevated serum creatinine.

we assessed age, sex, weight, height, body mass index (BMI), stone size, density, skin-to-stone distance (SSD), Hounsfield unit (HU), presence of JJ and presence of secondary signs (hydronephrosis, renal enlargement, perinephric fat stranding, and tissue rim sign).

Ethical approval:

The study was approved by the Ethics Board of AlAzhar University and an informed written consent was taken from each participant in the study.

The BMI was measured for each patient by dividing the patient's weight in kilograms by height in square meters. The SSD was measured on NCCT as the distances at $0^{\circ}, 45^{\circ}$ and $90^{\circ}$. The average is calculated as the SSD. The HU for each stone was determined by using a 5-mm collimation width from the top of the kidneys to the level of the pubic symphysis. Three regions of interest were analyzed. The $\mathrm{HU}$ average of three regions represented the $\mathrm{HU}$ for that stone. Secondary signs included the presence or absence of hydronephrosis, perinephric fat stranding and tissue rim sign. Hydronephrosis was distinguished by visualization of the dilated renal pelvicalyceal system. Perinephric fat stranding was defined as the stranding of adipose tissue around the kidney. Tissue rim sign was recognized as the observation of the annular soft tissue caused by edematous ureteral wall surrounding the stones. SWL sessions were generated using Dornier lithotripter SII. 
Fragmentation occurred under fluoroscopy. 3000 shocks was delivered at each session for adult and 1200 shocks for children at a rate of 80 shocks per minute with localization every 500 shocks. All patients were investigated two weeks after the first session by plain KUB to assess disintegration of stones and the need for further sessions. Fragments $4 \mathrm{~mm}$ or greater were considered as candidates for another SWL session. All patients were finally evaluated 3 months after the last session by plain KUB to assess stone free status. Clearance was documented by a plain film 2 weeks after the last SWL session, and defined as complete disappearance of the ureteral calculus. Fragments less than $4 \mathrm{~mm}$ were defined as clinically insignificant residual fragments (CIRF) and patients with CIRF were subsequently managed conservatively.

\section{Statistical analysis}

The data were analyzed to identify clinical and radiologic factors associated with treatment outcome. Univariate analysis was used to assess the association between the various factors and outcomes. Thereafter, the significantly associated variables were tested with multivariate logistic regression analysis to identify the independent predictors of treatment outcome. Values of $\mathrm{p} \leq 0.05$ were considered statistically significant.

\section{RESULTS}

102 patients with ureteric stones were included in the study. The success rate was $61.8 \%$ and the failure rate was $38.2 \%$. On univariate analysis, age (table 1) and sex (table 2) were not statistically significant. The mean stone size in the success and failure groups, respectively, was $9.3 \pm 2.2 \mathrm{~mm}$ and $11.2 \pm 2.2 \mathrm{~mm}$ ( $\mathrm{p}<$ 0.001 ) (table 1). The mean density of success group was $855 \pm 219$ and in failure group was $1039 \pm 267$ with statistically significance $(\mathrm{p}<0.001)($ table 2$)$.

The SSD (table 1), secondary signs (hydronephrosis, perinephric fat stranding and tissue rim sign) and JJ stent were statistically insignificant (table 2). Multivariate analysis revealed that both stone size and stone density were independent factors for SWL success (statistically significant, $\mathrm{p}$ value of size $=0.002$ and $p$ value of density $=0.003)($ table 3$)$.

Table (1): Univariate analysis of the factors in success and failure groups:

\begin{tabular}{|l|c|c|c|c|c|}
\hline & \multicolumn{2}{|c|}{ Failed } & \multicolumn{2}{c|}{ Success } & \\
\hline & Mean & SD & Mean & SD & P value \\
\hline Age & 41 & 14 & 37 & 12 & 0.105 \\
\hline BMI & 27.4 & 5.8 & 27.9 & 6 & 0.691 \\
\hline Size(mm) & 11.2 & 2.2 & 9.3 & 2.2 & $<\mathbf{0 . 0 0 1}$ \\
\hline Mean SSD & 10.1 & 0.9 & 10.1 & 0.8 & 0.830 \\
\hline Density & 1039 & 267 & 855 & 219 & $<\mathbf{0 . 0 0 1}$ \\
\hline
\end{tabular}

$\mathrm{SSD}=$ skin to stone distance, $\mathrm{SD}=$ standard deviation

Table (2): Univariate analysis of the factors in success and failure groups:

\begin{tabular}{|l|l|c|c|c|c|c|}
\hline \multirow{2}{*}{ Sex } & & \multicolumn{2}{|c|}{ Failed } & \multicolumn{2}{c|}{ Success } & \\
\cline { 3 - 6 } & & Count & \% & Count & \% & P value \\
\hline \multirow{2}{*}{ JJ stent } & Female & 9 & 39.1 & 14 & 60.9 & 0.920 \\
\cline { 2 - 6 } & Male & 30 & 38.0 & 49 & 62.0 & \\
\hline Tissue rim sign & Yes & 9 & 23.07 & 14 & 22.22 & 0.920 \\
\hline Perinephric stranding & Yes & 30 & 67.9 & 47 & 74.6 & 0.791 \\
\hline
\end{tabular}

$\mathrm{HN}=$ hydronephrosis

Table (3): Multivariate analysis

\begin{tabular}{|l|c|c|c|c|c|c|}
\hline & & & & & \multicolumn{2}{|c|}{ 95\% CI for OR } \\
\cline { 2 - 7 } & B & S.E. & p value & OR & Lower & Upper \\
\hline size $(\mathbf{m m})$ & 0.366 & 0.116 & 0.002 & 1.4 & 1.1 & 1.8 \\
\hline Density & 0.003 & 0.001 & 0.003 & 1.0 & 1.0 & 1.0 \\
\hline
\end{tabular}

$\mathrm{B}=$ Regression coefficients, $\mathrm{SE}=$ Standard error of the coefficient, OR=Odds Ratio, $95 \% \mathrm{CI}$ for OR $=95 \%$ confidence interval for the $=$ Odds Ratio. $\mathrm{P}$-value $\leq 0.05$ is considered significant 


\section{DISCUSSION}

Shock wave lithotripsy has been demonstrated to be a safe, effective, non-invasive, and easy way of treating upper ureteric stones. Recently, NCCT has been evaluated for the use not only in the diagnosis of stones but also for the prediction of SWL treatment results, which is analyzed by the use of various metrics; stone size, skin to stone distance and the stone density. Many radiological methods and parameters have been evaluated for their ability to predict stone fragility ${ }^{(6)}$. Our study included 102 patients underwent SWL. Outcome was $63(61.8 \%)$ patients successed and 39 $(38.2 \%)$ failed.

According to stone size, Goel $\boldsymbol{e t}$ al. evaluated 110 patients and divided them into 2 groups: group (A) 84 patients (76\%) and group (B) 26 patients (24\%). The mean stone size was $8.1 \mathrm{~mm}$ in group A (success) and 11.3 group B (failure), respectively. He concluded that the stone size was predictive factor for success of SWL $(\mathrm{p}<0.001)$. The larger stone size was found to be an independent predictor of failure of SWL on both univariate and multivariate analysis ${ }^{(5)}$.

Naoya et al. ${ }^{(7)}$ concluded that stone size was significant and independent predictor of success of SWL in patients with solitary proximal ureteral stone. The overall stone-free rate was $70 \%$ (223/319 patients). He divided the patients into 2 groups (success and failure). The mean and standard deviation of each group was $9 \pm 0.2 \mathrm{~mm}$ and $11 \pm 0.3 \mathrm{~mm}$ respectively ( $\mathrm{p}<$ 0.001 ). They found that the failure rate increase with large stone size. Ozgur et al. ${ }^{(\mathbf{(})}$ included in their study 160 patients with single ureteral stone ranging from 5 to $15 \mathrm{~mm}$ underwent SWL. He divided the patients into 2 groups: success $110(68.2 \%)$ and failure $50(31.8 \%)$ groups. The median stone size of each group was $9 \mathrm{~mm}$ $\& 10 \mathrm{~mm}$ respectively $(\mathrm{p}=0.349)$. They found that stone size was not an independent factor for success of SWL, and this may be the reason of narrow range of stone dimension. In our study, 102 patients were divided into 2 groups: success and failure groups. The stone size ranged from $6 \mathrm{~mm}$ to $17 \mathrm{~mm}$ and the mean stone size of each group was $9.3 \pm 2.2 \mathrm{~mm}$ and $11 \pm 2.2 \mathrm{~mm}$ respectively. We found that stones of patients in success group had a clinically significant lower mean stone size compared with stones of patients in failure group $(\mathrm{p}<0.001)$.

According to density of stone, Yusuke et al. ${ }^{(9)}$ evaluated 464 patients with ureteral stones who underwent SWL, $324(69.8 \%)$ patients were in success group and $140(30.2 \%)$ patients were in failure group. The mean HU of success and failure groups was 978.5 $\mathrm{HU}$ and $1280.5 \mathrm{HU}$ respectively. Significant differences were found in factors related to CT attenuation value $(\mathrm{p}=0.01)$. It was found that success rate increase with HU <1000. Goel et al. ${ }^{(5)}$ divided 110 patients into success group $=84(76 \%)$ and failure group $=26(24 \%)$ and divided the patients on the basis of $\mathrm{HU}$ into $\mathrm{A}(<750$ $\mathrm{HU}), \mathrm{B}(750-1000 \mathrm{HU}), \mathrm{C}(>1000 \mathrm{HU})$ of each success and failure groups. HU with a $(p=0.06)$ was not statistically significant, but HU was consistently low in the successful group ( $85 \%$ of success patients had HU <1000). Müllhaupt et al. ${ }^{(10)}$ in his study divided his 104 patients into success $52(50 \%)$ and failure $52(50 \%)$ groups. The mean HU value of success group was 956.9 $\mathrm{HU}$ and in failure group was $944.6 \mathrm{HU}$. Mean attenuation value was insignificant predictor for success of SWL $(P=0.373)$. He suggested that small sample size and narrow range of HU were the cause. Pareek $\boldsymbol{e t}$ al. ${ }^{(12)}$ correlated calculus density with clearance in a study of 50 patients who were treated with a second generation electrohydraulic lithotripter. They concluded that $36 \%$ of the patients with residual calculi had a mean calculus density of $\geq 900$ HU compared to a mean of $500 \mathrm{HU}$ in $74 \%$ of patients who had clearance. In our study, we divided 102 patients into success group (63 patients $=62 \%)$ and failure group (39 patient $=38 \%$ ). Each group was divided according to HU into < 700, 700-1000 and >1000. The mean \pm SD of each group was $855 \pm 219$ and $1039 \pm 267$ respectively. The density of success group was lower than those of failure group with significant independent predictor for outcome of SWL ( $p<0.001)$. Success rate in patients with $\mathrm{HU}<1000$ was $90 \%$ in success group.

According to SSD, Yusuke et al. ${ }^{(9)}$ evaluated 464 patients with ureteral stones who underwent SWL, $324(69.8 \%)$ patients were in success group and 140 $(30.2 \%)$ patients were in failure group. They found that SSD was significant predicting for outcome of SWL (p $<0.001$ ). The mean SSD of each group was $9.6 \mathrm{~cm}$ and $9.9 \mathrm{~cm}$ respectively. Goel $\boldsymbol{e t}$ al. ${ }^{(5)}$ divided 110 patients into success group $=84(76 \%)$ and failure group $=26$ (24\%) and found that SSD was not a significant predictor of the outcome of SWL $(P=0.913)$. The mean of each of success and failure groups was $90.0 \mathrm{~mm}$ and $96.0 \mathrm{~mm}$, respectively. Ozgur et al. ${ }^{(8)}$ included in his study 160 patients with single ureteral stone and divided them into success group $(110$ patients $=68 \%)$ and failure group $(50$ patients $=32 \%)$ and reported that SSD was insignificant for predicting outcome of SWL. The mean SSD of success group was $125 \pm 23 \mathrm{~mm}$ and the mean of failure group was $126 \pm 26 \mathrm{~mm}(\mathrm{p}=0.754)$.

Choi et al. (11) divided 153 patients into 2 groups: group A with stone size $\leq 10 \mathrm{~mm}$ and group B with stone size $>10 \mathrm{~mm}$. The success rates were $90.2 \%$ and $68.6 \%$ in group A and B respectively. The mean \pm SD of SSD for success and failure of each group was $102.4 \pm 12.88 \mathrm{~mm}, 110.8 \pm 5.66 \mathrm{~mm}$ in group $\mathrm{A}$ and $97.8 \pm 12.97 \mathrm{~mm}, 107.9 \pm 13.02 \mathrm{~mm}$ in group B respectively. SSD was significant predictor for outcome of SWL ( $\mathrm{P}<0.05)$. In our study, we divided 102 patients into success group 63 patients $(62 \%)$ and failure group 39 patient (38\%). There was no statistical significance for the SSD on SWL results in our study (p $>0.05$ ). The mean SSD for the success group was 10.1 $\pm 0.8 \mathrm{~cm}$ versus $10.1 \pm 0.9 \mathrm{~cm}$ for the failure group. This was because of narrow range of SSD.

According to secondary changes (hydronephrosis, perinephric fat stranding and tissue 
rim sign), Goel et al. ${ }^{(5)}$ found that presence of secondary changes was statistically significant $(P=$ 0.023 ) between success and failure groups in univariate and multivariate analysis. The changes in success group were present in 27 patients and not in 57 patients. In failure group, the changes were present in 15 patients and not in 11 patients ${ }^{(5)}$. Choi et al $^{\left({ }^{(1)}\right)}$ divided 153 patients into 2 groups: group A, stone size $\leq 10 \mathrm{~mm}$ and group $\mathrm{B}$, stone size $>10 \mathrm{~mm}$. All the secondary signs showed statistically significant differences of outcome of SWL ( $\mathrm{p}<0.05)$. Boulay et al. ${ }^{(\mathbf{1 3})}$ evaluated 99 patients and retrospectively analyzed the presence and severity of secondary signs of obstruction. The presence and severity of secondary signs of obstruction were not significantly different between the two groups and did not affect treatment. In our study, a total 102 patients were divided into success and failure groups. We found that there was no statistically significant difference between secondary changes and outcome of SWL (P > 0.05). It may be due to small sample size.

According to presence of JJ, Goel et al. ${ }^{(5)}$ found that presence of $\mathrm{JJ}$ was statistically insignificant $(P=$ 0.06 ) between success and failure groups. JJ in success group was present in 5 patients (7.2\%) and not in 64 patients $(92.8 \%)$ and in failure group was present in 8 patients $(19.5 \%)$ and not in 33 patients $(80.5 \%)^{(5)}$.

Müllhaupt et al. (10) reported that no significance differences for predicting success of SWL $(\mathrm{P}=0.825)$. The patients with JJ stent were 28 from total number 104 patients. He divided patients with $\mathrm{JJ}$ into success and failure groups. 15 patients were in success group and 13 patients were in failure group. Ghoneim et al. ${ }^{(14)}$ reported seventeen patients $(28.3 \%)$ received only one session, including 7 (23.3\%) in the stented group and $10(33.3 \%)$ in the unstented group. Patients required more than one session, were reported to be 43 patients $(71.7 \%)$, including $23(76.7 \%)$ in the stented group and $20(66.7 \%)$ in the unstented group. Although re-treatment rate was higher in the stented group. This was statistically insignificant difference. El-Assmy $\boldsymbol{e t}$ al. ${ }^{(15)}$ reported a higher success rate in unstented patients $(91.4 \%)$ than stented patients $(84.9 \%)$. This was insignificant difference. In our study, 102 patients were divided into success and failure groups. The presence of JJ in success group was 14 (22.22\%) patients and in $9(23.07 \%)$ patients in failure group. We found that there was no differences between stented and unstented patients for outcome of SWL ( $\mathrm{P}=0.920)$.

\section{CONCLUSION}

The study demonstrated that stone size and density are significant and independent predictors of outcome in patients with upper ureteral stones. However, SSD and signs of impaction still have to be evaluated.

\section{REFERENCES}

1. Chaussy C, Brendel W, Schmiedt E (1980): Extracorporeally induced destruction of kidney stones by shock waves. Lancet, 2: 1265-1268.

2. Motola JA, Smith AD (1990): Therapeutic options for the management of upper tract calculi. Urol Clin North Am., 17: 191-206.

3. El-Nahas AR, El-Assmy AM, Mansour O et al. (2007): A prospective multivariate analysis of factors predicting stone disintegration by extracorporeal shock wave lithotripsy: the value of high-resolution noncontrast computed tomography. Eur Urol., 51: 1688.

4. Abdel-Khalek M, Sheir K, Elsobky E et al. (2003): Prognostic factors for extracorporeal shock-wave lithotripsy of ureteric stones - A multivariate analysis study. Scand J Urol Nephrol., 37: 413-418.

5. Goel H, Gahlawat S, Bera MK et al. (2018): Role of clinical and radiological parameters in predicting the outcome of shockwave lithotripsy for ureteric stones. Urol Ann., 10: 159164.

6. Bon D, Dore B, Irani J et al. (1996): Radiographic prognostic criteria for extracorporeal shock-wave lithotripsy: a study of 485 patients. Journal of Urology, 48: 556-560.

7. Naoya N, Kazuhiro M, Makoto M et al. (2017): Simple and practical nomograms for predicting the stone-free rate after shock wave lithotripsy in patients with a solitary upper ureteral stone. world J Urol., 35: 1455-1461.

8. Ozgur Y, Murat T, Cahit S et al. (2015): Shock Wave Lithotripsy in Ureteral Stones: Evaluation of Patient and Stone Related Predictive Factors. Int Braz J Urol., 41: 676682.

9. Yusuke S, Takahiro K, Shigeru F et al. (2019): The usefulness of the maximum Hounsfield units (HU) in predicting the shockwave lithotripsy outcome for ureteral stones and the proposal of novel indicators using the maximum HU. Springer-Verlag GmbH Germany. Urolithiasis, 18: 64-68.

10. Müllhaupt G, Daniel S, Hans-Peter S et al. (2015): How do stone attenuation and skin-to stone distance in computed tomography influence the performance of shock wave lithotripsy in ureteral stone disease? BMC Urology, 15: 7278.

11. Choi JW, Song PH, Kim HT (2012): Predictive factors of the outcome of extracorporeal shockwave lithotripsy for ureteral stones. Korean J Urol., 53: 424-430.

12.Pareek G, Armenakas NA, Fracchia JA (2003): Hounsfield units on computerized tomography predict stonefree rates after extracorporeal shock wave lithotripsy. J Urol., 169: 1679-1681.

13. Boulay I, Holtz P, Foley WD et al. (1999): Ureteral calculi: diagnostic efficacy of helical CT and implications for treatment of patients. AJR Am J., 172: 1485-90.

14. Ghoneim IA, El-Ghoneimy MN, El-Naggar AE et al. (2010): Extracorporeal Shock Wave Lithotripsy in Impacted Upper Ureteral Stones: A Prospective Randomized Comparison between stented and nonstented Techniques. Urology, 75: 45-49.

15. EL-Assmy A, EL-Nahas AR, Sheir KZ (2006): Is pre-SWL stenting necessary for ureteral stones with moderate or severe hydronephrosis? J Urol., 176: 2059-2065. 